\title{
Supercapacitor application for PV power smoothing
}

\author{
Maria C. Argyrou \\ Department of Electrical \\ Engineering, Computer \\ Engineering and Informatics \\ Cyprus University of Technology \\ Limassol, Cyprus \\ $\underline{\text { mx.argyrou@edu.cut.ac.cy }}$
}

\author{
F. Paterakis \\ Department of Electrical and \\ Electronic Engineering \\ Athens University of Applied \\ Sciences \\ Athens, Greece \\ fpateras@gmail.com
}

\author{
Christina Panagi \\ Department of Electrical \\ Engineering, Computer \\ Engineering and Informatics \\ Cyprus University of Technology \\ Limassol, Cyprus \\ cp.panagi@edu.cut.ac.cy
}

\author{
Christos Makarounas \\ Department of Electrical \\ Engineering, Computer \\ Engineering and Informatics \\ Cyprus University of Technology \\ Limassol, Cyprus \\ christos.makarounas@cut.ac.cy
}

\author{
M. Darwish \\ School of Engineering and \\ Design \\ Brunel University \\ London, UK \\ mohamed.darwish@brunel.ac.uk
}

\author{
CC Marouchos \\ Department of Electrical \\ Engineering, Computer \\ Engineering and Informatics \\ Cyprus University of Technology \\ Limassol, Cyprus \\ christos.marouchos@cut.ac.cy
}

\begin{abstract}
The penetration of renewable energy technologies causes grid stability problems and voltage flickering due to fluctuations of the weather conditions, which affect the produced renewable power. The system is first analyzed in order to define the operating point and the controlling parameters, in which the produced power is shared correctly between the load and the grid at a power factor close to unity. The operating point is set by the duty cycle (D) of the DC-DC converter, the depth of modulation (Dm) of the inverter, and the phase angle $(\delta)$ between the output voltage of the inverter and the grid voltage. The simulated system is operated in an open-loop mode in order to investigate the effect of each parameter without the corrective action of the closed-loops of the MPPT and the load angle. After that, a preliminary investigation of a supercapacitor controlled storage application is performed in terms of the power flow. All calculated theoretical results are verified by the simulation results. This research forms the basis for an in-depth investigation of supercapacitor and battery storage in gridconnected systems.
\end{abstract}

Keywords-photovoltaics, net metering, supercapacitor, MPPT, smoothing

\section{INTRODUCTION}

The solar irradiation on the photovoltaic (PV) module is found to fluctuate (Fig.1) due to cloud movements, which cannot be predicted accurately. For example, when the clouds suddenly appear, the production will be decreased. This fluctuation on the solar irradiation is transmitted to the output power of the module and hence to the produced power of the system (Fig.2) [1]. The fluctuations of the PV produced power when injected to the grid cause power quality problems and affect the power system stability [2]. A possible solution is the use of a short-term energy storage technology to eliminate the fluctuation problems and improve these features [3]-[6].

Energy storage is necessary nowadays because of the increased penetration of Renewable Energy Sources (RES) and distributed generation. The increased penetration of Renewable Energy Sources may cause several stability problems, affecting the quality and reliability of the utility grid. Therefore, energy storage can be integrated into a renewable system providing power and voltage smoothing, peak shaving, load levelling, emergency generation or energy management [5], [7]-[9]. There are various energy storage methods to be used [10]. The selection of the proper storage solution depends on several factors, such as the storage capacity size (small-scale or large-scale), the duration of discharge time (short-term or long-term), the energy efficiency levels and the cost requirements [11]-[13]. In this paper, a power smoothing application on a PV system using a supercapacitor storage system is examined.

The system under investigation is a $3 \mathrm{KW}_{\mathrm{p}}$ Net metering configuration employing 12 Luxor ECO Line PV modules of 250W [14], supplying the load and the grid (Fig.3). The Maximum Power Point (MPP) of the PV array is displayed in Table I for a number of irradiation levels. The system is modelled in PSIM software [15], but first the mathematics for sharing the PV produced power between the load and the grid are developed in terms of the grid voltage $V_{\text {Grid, }}$, the inverter voltage $V_{\text {inv }}$, the grid current $I_{\text {Grid, }}$, the inverter current $I_{\text {inv }}$ and the phase angle between the grid voltage and the inverter voltage $\delta$. From this analysis the value of $\delta$ is derived from a relevant graph (Fig.4). Cloud movement and other reasons disturb the solar irradiation on the PV modules. This causes reduction of delivered power, reduction in current supplied to the inverter, the dramatic deterioration of the power factor, voltage flickering and frequency stability to the utility grid. On our model we can observe the reduction of delivered power, reduction in current supplied to the inverter and the deterioration of the power factor. Of course the later can be restored when the system is "tuned" to the new irradiation by setting D, Dm and $\delta$ accordingly (Fig. 7). 
The lost power to the grid due to the disturbance can be restored by partial storage. This will alleviate the problem of voltage flickering and frequency stability of the grid. In this paper, the application of supercapacitors is partially investigated in terms of the power flow.

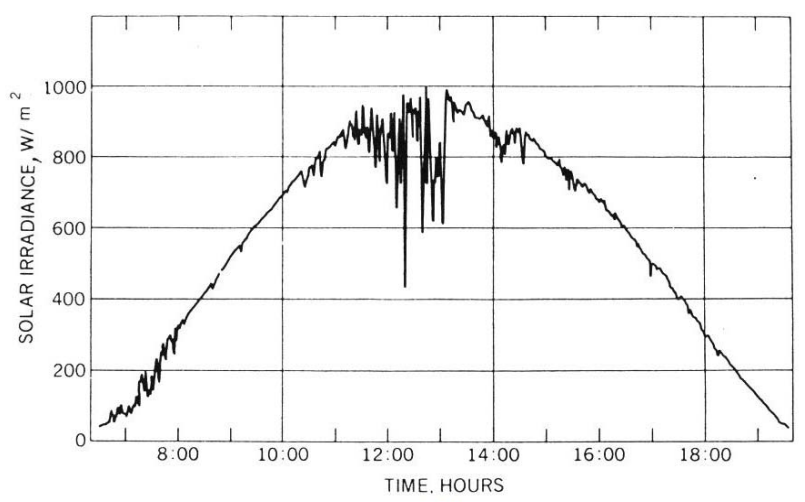

(a)

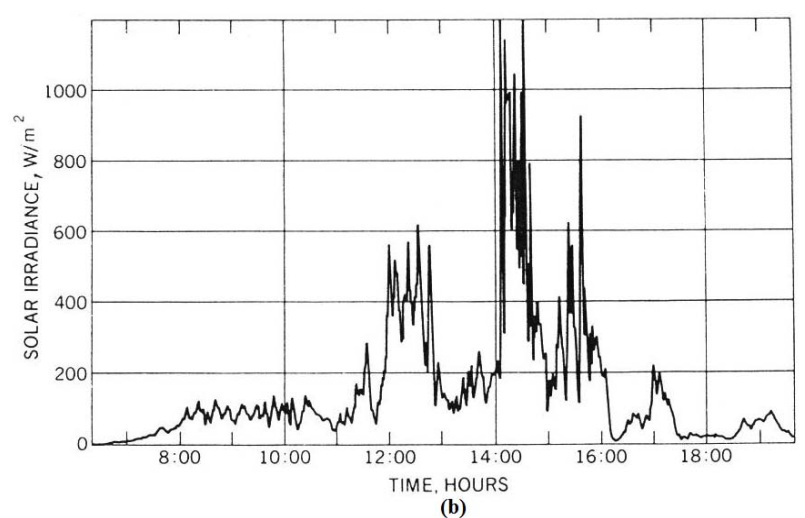

Fig. 1. Typical disturbances of the sun irradiation during the day for (a) mostly sunny day and (b) mostly cloudy day [1]

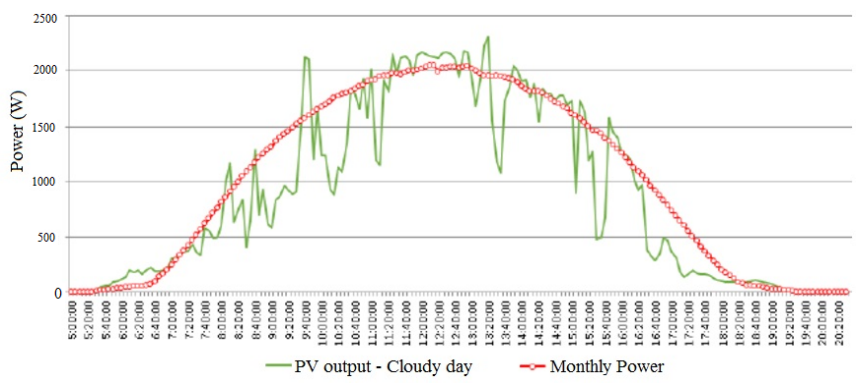

Fig. 2. Produced power over a typical day with disturbances (green) and average produced power over a month (red)

\section{Mathematical ANALYSIS}

The system is analysed for three cases with regard to the solar power sharing between the load and the grid. In Case A the produced power $\left(\mathrm{P}_{\text {solar }}\right)$ exceeds the load demand $\left(\mathrm{P}_{\text {load }}\right)$ and the excess power is fed to the grid $\left(\mathrm{P}_{\text {grid }}\right)$, as given below:

$$
\mathrm{P}_{\text {Solar }}=\mathrm{P}_{\text {Load }}+\mathrm{P}_{\text {Grid }}
$$

In case B the produced power is less than the load. Therefore, the load is supplied by both the solar power and the grid, as given in (2).

$$
\mathrm{P}_{\text {Load }}=\mathrm{P}_{\text {Solar }}+\mathrm{P}_{\mathrm{Grid}}
$$

Case C is a special case of Case A where the load is zero and all the produced solar power is fed to the grid.

$$
\mathrm{P}_{\text {Solar }}=\mathrm{P}_{\text {Grid }}
$$

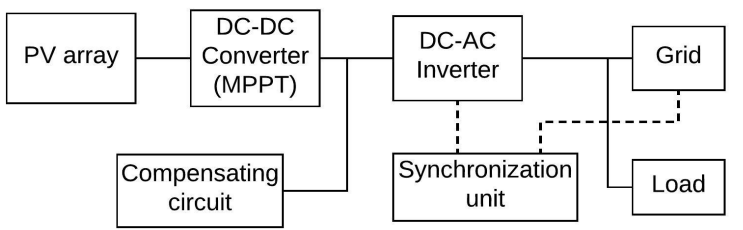

Fig. 3. The PV system supplying the load and the grid with compensation circuit

\section{A. Case A}

The produced power exceeds load demand and the excess power is fed to the grid. The Voltage of the Inverter $\left(\mathrm{V}_{\text {inv1 }}\right)$ leads the grid voltage $\left(\mathrm{V}_{\text {Grid }}\right)$ by $\delta$. Equation (4) presents an expression for the derived solar power in terms of the load power $\left(\mathrm{P}_{\text {Load }}\right)$, the grid voltage $\left(\mathrm{V}_{\text {Grid }}\right)$, the inverter voltage $\left(\mathrm{V}_{\text {inv1 }}\right)$ and the phase angle between the grid voltage and the inverter voltage $(\delta)$.

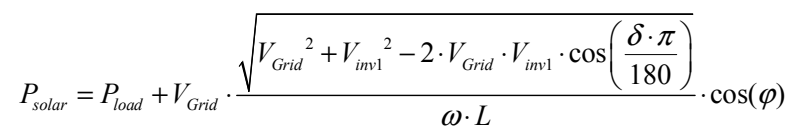

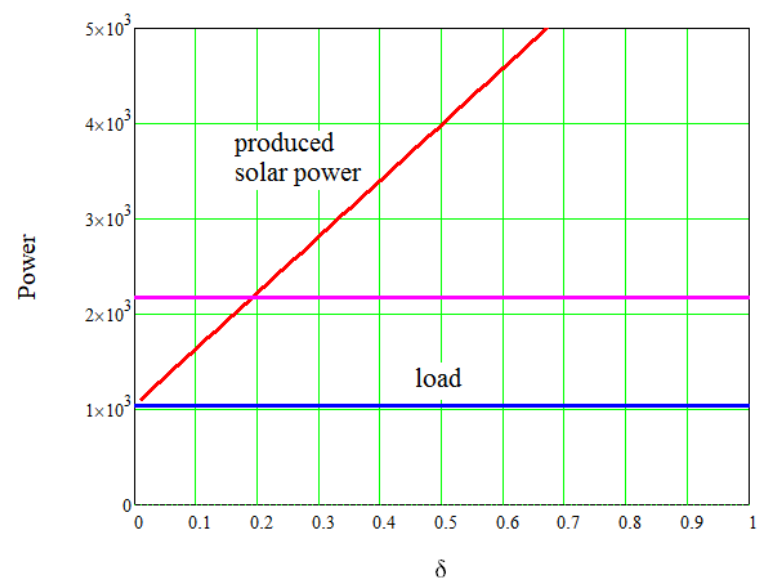

Fig. 4. Produced solar power (red) and load lines (blue and pink) in terms of power angle $\delta$ for case A

Fig.4 is a graphical presentation of (4). From this graph the necessary value of $\delta$ is derived for the correct power sharing according to (1). For example, for a produced solar power of $2.171 \mathrm{KW}$ and a load of $1 \mathrm{KW} \delta$ must be in the order of 0.2 degrees. 


\section{B. Case B}

The produced power is less than the load demand and the rest of the required power is supplied by the grid. The Voltage of the Inverter $\left(\mathrm{V}_{\mathrm{inv1}}\right)$ lags the grid voltage $\left(\mathrm{V}_{\mathrm{Grid}}\right)$ by $\delta$. Equation (5) shows the relationship between the derived solar power in terms of the load power $\left(\mathrm{P}_{\text {Load }}\right)$, grid voltage $\left(\mathrm{V}_{\mathrm{Grid}}\right)$ the inverter voltage $\left(\mathrm{V}_{\text {inv1 }}\right)$ and the phase angle $\delta$.

$$
P_{\text {solar }}=P_{\text {load }}-V_{\text {Grid }} \cdot \frac{\sqrt{V_{\text {Grid }}^{2}+V_{\text {inv1 }}^{2}-2 \cdot V_{\text {Grid }} \cdot V_{\text {inv1 }} \cdot \cos \left(\frac{\delta \cdot \pi}{180}\right)}}{\omega \cdot L} \cdot \cos (\varphi)
$$

Fig.5 is a graphical presentation of (5). From this graph the necessary value of phase $\delta$ can be obtained.

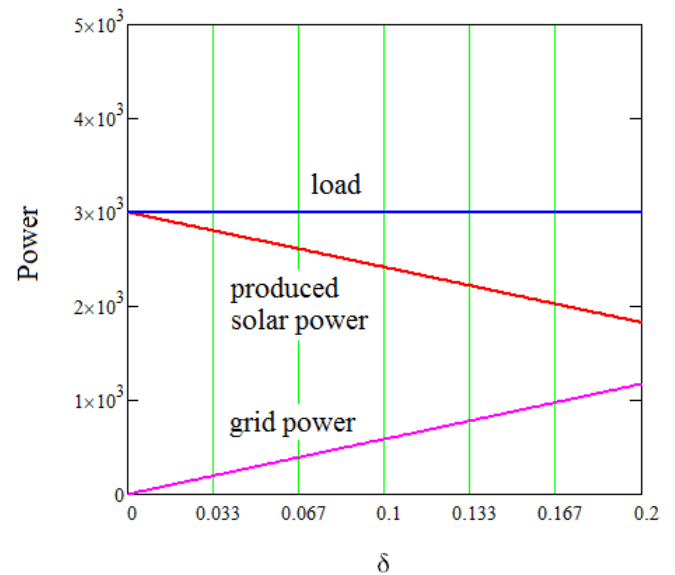

Fig. 5. Produced solar power (red), grid power (pink) and load (blue) in terms of power angle $\delta$ for case B

\section{Case C}

For this case, the load demand is zero and all the produced power is fed to the grid. Case $\mathrm{C}$ is a special case of Case A. The voltage of the inverter $\left(\mathrm{V}_{\text {inv1 }}\right)$ leads the grid voltage $\left(\mathrm{V}_{\mathrm{Grid}}\right)$ by $\delta$. An expression for the derived solar power in terms of the inverter voltage $\left(\mathrm{V}_{\text {inv1 }}\right)$ and the phase angle $\delta$ is presented in (6).

$$
P_{\text {solar }}=V_{\text {Grid }} \cdot \frac{\sqrt{V_{\text {Grid }}^{2}+V_{i n v 1}^{2}-2 \cdot V_{\text {Grid }} \cdot V_{i n v 1} \cdot \cos \left(\frac{\delta \cdot \pi}{180}\right)}}{\omega \cdot L} \cdot \cos (\varphi)
$$

Fig.6 is a graphical presentation of (6). From this graph the necessary phase $\delta$.

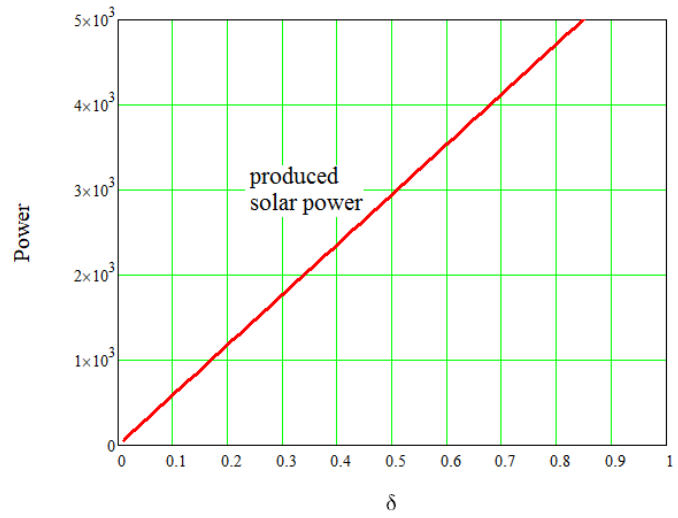

Fig. 6. Produced solar power in terms of power angle $\delta$ for Case $C$

\section{MOdelling Of THE SySTEM IN PSIM}

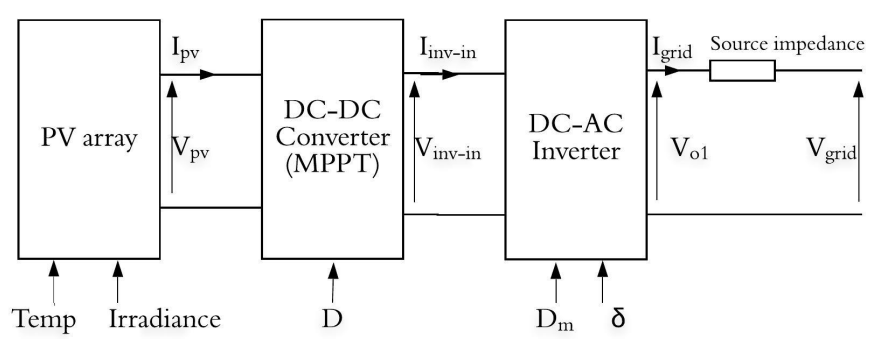

Fig. 7. The system as simulated in PSIM without the storage circuit

The system in Fig.7, is first simulated in PSIM without the smoothing circuit. This case is examined in order to confirm the correct operation of the circuit in terms of power sharing at the calculated parameters of the system. These parameters are the phase angle $\delta$ and the controlling parameters of the MPPT and the Inverter, D and Dm correspondingly.

The DC-DC converter provides the Maximum Power Point (MPP) for the operation of the PV system and keeps the output voltage at $400 \mathrm{~V}$. This is the reference voltage at the input of the inverter. The input to the MPPT is the voltage and current of the Photovoltaic array. There are various MPPT techniques to be used [16]-[19]. Here, the Perturbation and Observation, which is a hill climbing method is used. The variable for perturbation is the duty cycle D. For each level of solar irradiation there is a set of voltage and current values that the PV system can give the maximum power. This is the Maximum Power Point as shown in Table I. These results are derived from the simulation of the PV system in PSIM.

TABLE I. MAXIMUM POWER POINTS For ECO LINE LUXOR LX250P

\begin{tabular}{|c|c|c|c|}
\hline $\begin{array}{c}\text { Irradiance } \\
\left(\mathbf{W} / \mathbf{m}^{2}\right)\end{array}$ & $\mathbf{P}_{\mathbf{m p p}}(\mathbf{W})$ & $\mathbf{I}_{\mathbf{m p p}}(\mathbf{A})$ & $\mathbf{V}_{\mathbf{m p p}}(\mathbf{V})$ \\
\hline 200 & 537 & 3.21 & 167.3 \\
\hline 400 & 1080 & 6.1 & 176.98 \\
\hline 600 & 1650.24 & 9.6 & 171.9 \\
\hline 800 & 2171.08 & 12.92 & 168.04 \\
\hline 1000 & 2681.76 & 15.6 & 171.9 \\
\hline
\end{tabular}


The controlling parameter of the MPPT is calculated for a boost converter circuit from:

$$
D=\frac{V_{\text {inv-input }}-V_{P V}}{V_{\text {inv-input }}}
$$

The controlling parameter of the Inverter is calculated from:

$$
D m=\frac{V_{i n v 1}}{V_{\text {inv-input }}}
$$

The case of $800 \mathrm{~W} / \mathrm{m}^{2}$ and a load of $1 \mathrm{KW}$ is simulated. As shown in Table II the PV modules have a voltage of $168.04 \mathrm{~V}$ for the operation at the Maximum Power which is $2171 \mathrm{~W}$. Hence D is calculated as 0.5799 . The output of the inverter is set to $325 \mathrm{~V}_{\text {peak }}$ and $\mathrm{Dm}$ is calculated as 0.8125 . The phase angle $\delta$ is derived graphically from Fig. 4, for a load of $1 \mathrm{KW}$ as $\delta=0.196$.

These values of D, Dm and $\delta$ are used to simulate the circuit in PSIM. It is found that the system performs as expected, and the results are shown in Table II.

TABLE II. RESUlts OF SimULATION FOR CASE A

\begin{tabular}{|l|l|l|l|l|l|l|}
\hline & $\begin{array}{l}\mathbf{P}_{\text {mpp }} \\
(\mathbf{W})\end{array}$ & $\begin{array}{l}\mathbf{I}_{\text {mpp }} \\
(\mathbf{A})\end{array}$ & $\begin{array}{l}\mathbf{V}_{\text {mpp }} \\
(\mathbf{V})\end{array}$ & $\begin{array}{l}\mathbf{V d c} \\
(\mathbf{V})\end{array}$ & $\mathbf{p f}$ & $\begin{array}{l}\mathbf{V}_{\text {inv1 }} \\
(\mathbf{V})\end{array}$ \\
\hline Theoretical & 2171.0 & 12.92 & 168.04 & 400 & 1 & 325 \\
\hline Simulation & 2171.5 & 12.947 & 167.72 & 400 & 0.967 & 324.7 \\
\hline
\end{tabular}

We observe that there is a slight discrepancy between theoretical and simulation results but in general there is a good agreement. This means we can proceed to try the controlled smoothing.

\section{CONTROLlED SMOOTHING}

In the system under investigation there is no automatic Maximum Power point tracking neither automatic power angle control. Controlled smoothing is applied via the compensating circuit (Fig.3). The compensating circuit is simply a bidirectional dc/dc step up converter which connects a charged supercapacitor module to the input of the inverter. The $50 \mathrm{~F}$ supercapacitor is charged during the non-disturbance periods to $100 \mathrm{~V}$. The equivalent circuit used for the supercapacitor is the simplest one consisting of a capacitor and an equivalent series resistor (ESR), as shown in Fig. 8. The series resistor represents the losses. There are many suggested equivalent circuits for the supercapacitor in the literature [8], [20]-[22].

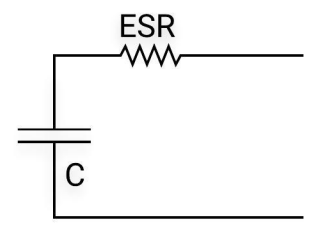

Fig. 8. Supercapacitor simple equivalent model
The disturbances of the sun irradiation on the PV modules due to clouds movements, is simulated by a sudden drop of the irradiation from $1000 \mathrm{~W} / \mathrm{m}^{2}$ to $200 \mathrm{~W} / \mathrm{m}^{2}$ for about two seconds (Fig. 9). As shown in Fig. 9, the irradiation disturbance has an effect on the PV current. Naturally the sudden fall of solar power has an effect on the PV module. The PV current at the Maximum Power Point for irradiance $1000 \mathrm{~W} / \mathrm{m}^{2}$ is $16 \mathrm{~A}$ and during the disturbance it falls to $3.21 \mathrm{~A}$ (current at the maximum power for irradiation $200 \mathrm{~W} / \mathrm{m}^{2}$ ). This is also in accordance with Table I. Observing Table I, it is obvious that the voltage at the maximum power point remains almost unchanged. Additionally, the power factor of the delivered power to the grid falls from 0.997 to 0.659 . The power delivered to the grid during the non-disturbance period is $2.594 \mathrm{KW}$. During the disturbance it is only $0.453 \mathrm{KW}$ without compensation. With compensation it is increased to $1.970 \mathrm{KW}$ and the compensating circuit provides the rest which is $1.516 \mathrm{KW}$. This power is stored in the $50 \mathrm{~F}, 100 \mathrm{~V}$ supercapacitor module. Measured voltages and currents at the supercapacitor confirm this level of compensating power.

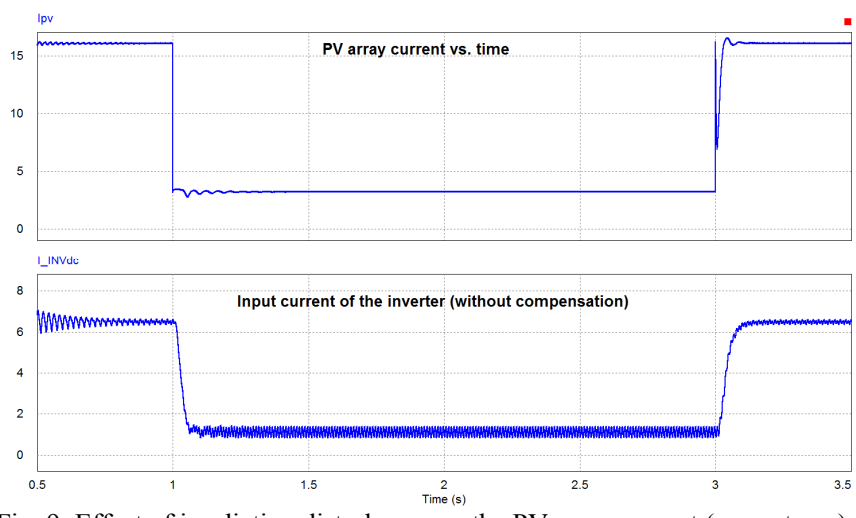

Fig. 9. Effect of irradiation disturbance on the PV array current (upper trace) and on the input current of the inverter (lower trace)

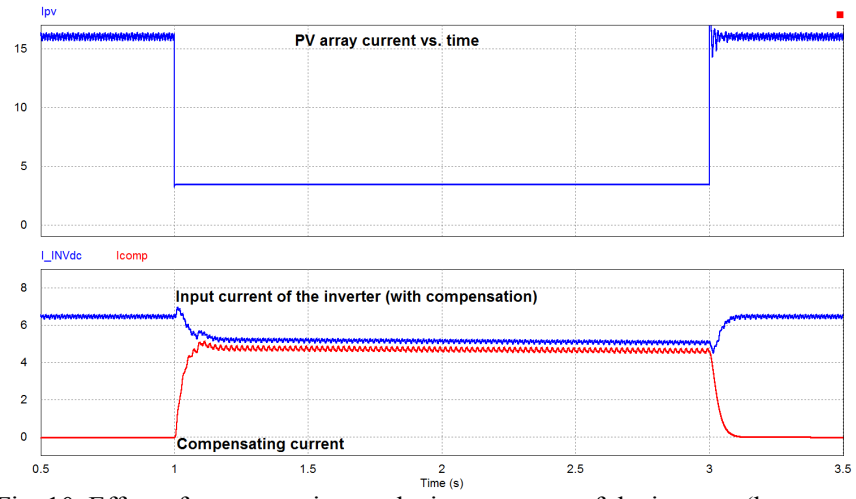

Fig. 10. Effect of compensation on the input current of the inverter (lower trace)

As can be seen in Fig.10, the application of the compensating circuit improves the performance of the system dramatically. After a transient period, the current to the inverter and the power flow to the grid are close to their original values. The current to the inverter during the compensating period is 
4.888A. The PV array provides $1.127 \mathrm{~A}$ and the compensating circuit the rest in the order of $3.722 \mathrm{~A}$.

\section{CONCLUSIONS AND FutURE WORK}

The basis for further and more extensive investigation of storage in PV systems installed in homes is presented in this paper. The presence of the load is accounted for and the importance of the controlling parameters is highlighted. Future work will be concentrated on efficient bidirectional DC-DC converters to deliver the stored power to the grid during disturbance and storing energy during non-disturbance periods. Methods to identify the disturbance and its level must also be investigated. The quality of the power during the disturbance with compensation is of paramount importance. Furthermore, the appropriate equivalent circuit of the supercapacitor model device will be examined in terms of its electrical and other characteristics.

The PV system which is usually installed in homes where the surplus power is fed to the grid is thoroughly analyzed mathematically and then simulated on PSIM. The results agree reasonably. It is shown that the operating point of the system is defined by the maximum power Point of the PV modules $\left(\mathrm{V}_{\mathrm{mpp}}, \mathrm{I}_{\mathrm{mpp}}\right)$, the input voltage to the inverter (normally $400 \mathrm{~V}$ ), the output voltage of the inverter (normally $230 \mathrm{~V}_{\mathrm{rms}}$ ) and the sharing of the produced PV power with the grid and the load. It was also shown mathematically and by simulation that the operating point is set by the controlling parameter of the MPPT, parameter D (Duty-Cycle), by the controlling parameters of the inverter, the depth of modulation Dm and the phase angle $\delta$. Both theoretical and simulation results agree reasonably. Partial Controlled Storage was applied in order to alleviate the problem of irradiation disturbance. This was done by the compensating circuit which simply discharges a supercapacitor at the input of the inverter in order to keep the current at the input of the inverter unchanged. It is shown that during a disturbance the supercapacitor module must provide high power-almost the load power- for short periods of time. Therefore its voltage currents ratings are important in selecting the appropriate one. This is one of the objectives of further research.

\section{REFERENCES}

[1] M. P. Thekaekara, "Solar radiation measurement: Techniques and instrumentation," Sol. Energy, vol. 18, no. 4, pp. 309-325, 1976.

[2] D. Parra, G. S. Walker, and M. Gillott, "Modeling of PV generation, battery and hydrogen storage to investigate the benefits of energy storage for single dwelling," Sustain. Cities Soc., vol. 10, pp. 1-10, 2014

[3] M. Beaudin, H. Zareipour, A. Schellenberglabe, and W. Rosehart, "Energy storage for mitigating the variability of renewable electricity sources: An updated review," Energy Sustain. Dev., vol. 14, no. 4, pp. 302-314, 2010.

[4] T. Senjyu, M. Datta, A. Yona, and T. Funabashi, "PV Output Power Fluctuations Smoothing and Optimum Capacity of Energy Storage
System for PV Power Generator," Icrepq.Com, pp. 3-7, 2008.

[5] H.-R. Seo, G.-H. Kim, S.-Y. Kim, N. Kim, H.-G. Lee, C. Hwang, M. Park, and I.-K. Yu, "Power quality control strategy for gridconnected renewable energy sources using PV array and supercapacitor," Int. Conf. Electr. Mach. Syst., pp. 437-441, 2010.

[6] L. Wang, Q.-S. Vo, and A. V Prokhorov, "Stability Improvement of a Multimachine Power System Connected with a Large- Scale Hybrid Wind-Photovoltaic Farm Using a Supercapacitor," IEEE Trans. Ind. Appl., vol. 54, no. 1, pp. 50-60, 2018.

[7] Y. Ghiassi-Farrokhfal, S. Keshav, and C. Rosenberg, "Towards a realistic performance analysis of storage systems in smart grids," IEEE Trans. Smart Grid, vol. 6, no. 1, pp. 402-410, 2015.

[8] A. Zahedi, "Maximizing solar PV energy penetration using energy storage technology," Renew. Sustain. Energy Rev., vol. 15, no. 1, pp. 866-870, 2011.

[9] R. Carnegie, D. Gotham, D. Nderitu, and P. V. Preckel, "Utility Scale Energy Storage Systems: Benefits, Applications, and Technologies," State Util. Forecast. Gr., 2013.

[10] M. C. Argyrou, P. Christodoulides, and S. A. Kalogirou, "Energy Storage for electricity generation and related processes: Technologies appraisal and grid scale applications," Renew. Sustain. Energy Rev., vol. 94, pp. 804-821, 2018.

[11] M. G. Molina, "Energy Storage and Power Electronics Technologies : A Strong Combination to Empower the Transformation to the Smart Grid," Proc. IEEE, 2017.

[12] C. Naish, I. McCubbin, O. Edberg, and M. Harfoot, "Outlook of energy storage technologies," Eur. Parliam. Comm. Ind. Res. Energy, 2008.

[13] S. M. Schoenung, "Characteristics and Technologies for Long-vs. Short-Term Energy Storage : A Study by the DOE Energy Storage Systems Program," United States Dep. Energy, 2001.

[14] Luxor, "Solar module Eco Line 60/230-250W, LX-250P." [Online]. Available: https://www.luxor-solar.com/en/solar-modules/ecoline/eco-line-classic.html.

[15] Powersim, "PSIM." [Online]. Available: https://powersimtech.com/products/psim/

[16] B. Subudhi and R. Pradhan, "A Comparative Study on Maximum Power Point Tracking Techniques for Photovoltaic Power Systems," IEEE Trans. Sustain. Energy, vol. 4, no. 1, pp. 89-98, 2013.

[17] H. Rezk and A. M. Eltamaly, "A comprehensive comparison of different MPPT techniques for photovoltaic systems," Sol. Energy, vol. 112, pp. 1-11, 2015.

[18] T. Esram and P. L. Chapman, "Comparison of Photovoltaic Array Maximum Power Point Tracking Techniques," IEEE Trans. Energy Convers., vol. 22, no. 2, pp. 439-449, 2007.

[19] M. C. Argyrou, P. Christodoulides, and S. A. Kalogirou, "Modeling of a photovoltaic system with different MPPT techniques using MATLAB / Simulink," in 2018 IEEE International Energy Conference (ENERGYCON), 2018.

[20] A. B. Cultura and Z. M. Salameh, "Modeling, Evaluation and Simulation of a Supercapacitor Module for Energy Storage Application," in Proceedings of the International Conference on Computer Information Systems and Industrial Applications (CISIA), 2015, pp. 876-882.

[21] C. Lungoci and I. D. Oltean, "About Supercapacitors Parameters Determination," Bull. Transilv. Univ. Braşov, vol. 2, no. 51, pp. 279-286, 2009.

[22] R. Faranda, M. Gallina, and D. T. Son, "A new simplified model of Double-Layer Capacitors," 2007 Int. Conf. Clean Electr. Power, pp. 706-710, 2007. 